\title{
Entrevista a Juan Villoro Apuntes para un elogio del ornitorrinco
}

\author{
INTERVIEW WITH JUAN VILLORO \\ NOTES FOR A PLATYPUS STORY
}

Alonso Rabí do Carmo

Universidad de Lima

arabi@ulima.edu.pe

Juan Villoro, escritor y periodista mexicano nacido en 1956, es actualmente uno de los principales cronistas latinoamericanos de nuestra época. Autor de novelas, cuentos y notables ensayos, su pasión por la crónica lo ha llevado a elaborar una teoría sobre este popular género en América Latina. Se trata, nada menos, de considerar la crónica como un "ornitorrinco", analogía apropiada para un discurso que reúne elementos de distinta procedencia y los mezcla funcionalmente, como un ornitorrinco, que reúne cualidades de diversos animales: es mamífero, ovíparo, vive buena parte de su vida en el agua, tiene pico de pato y cola de castor. En esta entrevista, Juan Villoro recuerda sus antecedentes familiares, el modo en que construyó su vocación de escritor y, naturalmente, practica agudas reflexiones sobre la crónica.

En el 104 de la calle de Donceles, que concentra algunas de las mejores librerías de viejo en Ciudad de México, se ubica el Colegio Nacional, una institución humanista que promueve la investigación y los quehaceres del pensamiento en el ámbito mexicano. El Colegio Nacional, según sus detractores, es una suerte de club de ilustrados. No tiene por qué extrañar el lance, porque en todas partes se cuecen habas. Lo cierto es que el Colegio Nacional es una institución importante porque cumple con una labor que en otros países ya empieza a sonar no quijotesca (que eso habría que tomarlo como un elogio), sino idiota: estimular el acercamiento y estudio de las humanidades.

Una mañana de abril del 2017 llegué a la puerta del colegio con un equipo del canal 7, pues teníamos una cita con uno de los miembros más destacados de este colectivo intelectual: Juan Villoro, escritor y ensayista, autor de una vasta obra que ha explorado diversos aspectos de la vida de su país (extensibles por supuesto a América Latina), que van desde la corrupción y la violencia hasta la segunda religión de muchos de nuestros países: el fútbol. Villoro, que por confesión propia es hincha irredento del Necaxa -igual que Don Ramón, el entrañable y eterno desempleado de la vecindad del Chavo-, sabe muy bien que Dios es redondo, como reza uno de sus libros más conocidos.

Algunos datos para comenzar un rompecabezas biográfico que está en construcción permanente. Juan Villoro nació en México en 1956. Su padre, Luis Villoro, catalán, era filósofo; su madre, Estela Ruiz Milán, se dedicó a ejercer el psicoanálisis. Sus dos primeras novelas, El disparo de Argón (1991) y Materia dispuesta (1997), son parte del camino que lo conduce a la consagración internacional con El testigo (2004), ganadora indiscutible del Premio Herralde de ese año. Villoro lleva varias décadas dedicado a escribir ficción y ensayo, además de crónicas y reportajes que por su excelencia y rigor forman parte ya del canon del periodismo narrativo latinoamericano de las últimas décadas.

doi: https://doi.org/10.26439/en.lineas.generales2021.n6.5598

Recibido: 7.12.2020 / Aprobado: 26.3.2021 
Su faceta de ensayista es muy destacable también. Dos libros vienen a mi memoria al escribir estas líneas, dos libros escritos con inteligencia, con sutileza, con auténtico y riguroso compromiso con la lectura literaria. El primero de ellos es Efectos personales (2001), en el que bastará recorrer, por citar un caso, las agudas páginas que dedica a Rulfo para darse cuenta del brillo y el celo que pone en cada palabra, o La utilidad del deseo (2017), donde tuve la suerte de leer una de las mejores aproximaciones al sentido de la gran literatura rusa (Tolstói, Dostoievski, Chéjov, Gógol y otros).

Tres años después de ese primer encuentro, en algún momento de la pandemia, pude volver a dialogar con Villoro, esta vez vía Zoom, para el programa Presencia cultural, que tuve el honor de conducir. Por artes del oficio, he mezclado los dos diálogos, sin faltar al estilo oral ni a las cosas dichas por el brillante escritor mexicano.

\section{Me gustaría comenzar por un dato de tu biografía que me parece interesante. Eres hijo de un filósofo y una psicoanalista. No es una mezcla común, ¿verdad?}

Es muy curioso, en efecto. Para mí, cuando era niño, la profesión de mi padre resultaba muy extraña, pues en la escuela, cuando nos preguntábamos por los oficios de nuestros padres, unos decían "mi papá es ingeniero" o "mi papá es piloto" o "mi papá es doctor o vendedor", en fin, todos oficios comprensibles. De pronto me preguntaban a qué se dedicaba mi padre y yo respondía: “Bueno, pues, es filósofo". “¿Y qué es eso?”, replicaban. Y ahí iba yo de nuevo: "Bueno, pues, un filósofo se dedica a entender el sentido de la vida". Eso me había dicho mi padre que respondiera, pero lo que mis amigos realmente pensaban es que mi papá era una suerte de bohemio incurable que se la pasaba en las cantinas bebiendo tequila y oyendo mariachis, porque para ellos eso graficaba a un adulto buscando el sentido de la vida: alguien medio perdido oyendo por ahí canciones rancheras (risas). De manera que durante mi infancia y mi adolescencia no me fue muy fácil entender el oficio de mi padre.

\section{¿Y en relación con tu madre?}

Ella era psicóloga. Y eso era mucho más comprensible. Ella trabajaba en un hospital psiquiátrico infantil, estaba a cargo de un pabellón. Trabajaba con niños que tenían debilidades mentales muy profundas y muchas veces llegaba a casa agotada, sobrecargada con esos problemas, y entonces ya no tenía tiempo para ocuparse de nuestras propias debilidades caseras. Luego, al paso de los años, se formó como psicoanalista. A la larga diría que fue provechoso tener este tipo de padres, pero solo a la larga, cuando entendí el valor de los libros y la cultura, y tuve la posibilidad de discutir con ellos de temas que durante la infancia no habría podido vislumbrar. La verdad es que al menos durante la infancia hubo cierta extrañeza frente a los oficios de mis padres. Mi infancia, además, corresponde a una etapa en la que no abundaban los libros infantiles ni los padres participaban, como ahora, de los juegos de los niños. Mi madre un poco más, es verdad, pero mi padre, como los padres de esos tiempos, y no lo digo con resentimiento, no se metía mucho en nuestro mundo. Más bien era yo quien intentaba acercarme al suyo. 


\section{¿Cuál fue el factor de unión más fuerte?}

Sin ninguna duda el fútbol. Desde mi infancia el fútbol fue un gran lugar de encuentro con mi padre. Él era aficionado y gracias a eso yo me volví aficionado también. Me llevaba todos los domingos al estadio y ahí sí compartimos ese mundo común de mitologías futboleras y acaso por eso me convertí en un apasionado de este deporte.

\section{¿Él te hizo hincha del Necaxa?}

No, no. Él, como buen profesor universitario, era hincha de los Pumas, el equipo de la UNAM. Su primer amor, en todo caso, fue el Asturias, uno de los equipos españoles que había en México (mi padre nació en Barcelona) y cuando los Pumas suben a la primera él siente la obligación "ideológica" (risas) de apoyarlos. Yo era y soy hincha del Necaxa, como bien has dicho. Por alguna razón, la mayoría de los chicos de mi calle eran aficionados del Necaxa, eran necaxistas. Un equipo simpático que llegó a ganarle al Santos con Pelé y todo, un equipo que rara vez campeonaba, pero tenía partidos sorprendentes. Me hice hincha del Necaxa para estar a tono con mi barrio, acercarme a su gente, ser miembro de esa tribu y eso me convirtió en el necaxista sufrido que soy hasta hoy.

\section{Uno siempre quiere saber cómo empieza un escritor su vida en la literatura. ¿Cómo se explica eso en tu caso?}

Como casi todo el mundo, yo llegué por accidente a la literatura. A la lectura, para ser más precisos, que es lo que antecede a la escritura. A ver, tenía quince años y yo no era un gran lector ni tenía ninguna pasión literaria. Mi casa tampoco estaba poblada de libros, así que mi infancia tampoco fue marcada por nada libresco. Además, hasta los quince años, la escuela no había despertado nada literario en mí, ni un ápice. Sin embargo, en las vacaciones previas al bachillerato (equivalente mexicano del periodo preuniversitario), un amigo del barrio me regaló una novela, De perfil, de José Agustín, que precisamente narraba la vida de un adolescente que como yo estaba en esas vacaciones aquí en Ciudad de México. Su lectura me fascinó porque fue como verme en el espejo...

\section{Como si José Agustín la hubiese escrito para ti...}

Sí, claro, sentí eso, como seguramente otros adolescentes con la misma vanidad sintieron. Entonces esa lectura fue un parteaguas. Desde ese momento tuve la sensación de que la literatura podía incluir incluso a alguien tan poco interesante como yo (risas), es decir que mis días sin brújula y llenos de sinsentido, si se narraban bien, podían ser una versión de picaresca maravillosa. 
En nuestras tradiciones literarias existe siempre una especie de gran padre. En el Perú ese lugar sin duda alguna lo ocupa Vallejo. Quiero creer que esa figura en México corresponde a Rulfo. ¿De quién hablamos cuando hablamos de Rulfo?

Hablamos del mayor narrador mexicano. Hablamos de un escritor absolutamente formidable que mantiene una vigencia única. Desde un punto de vista testimonial, muy pronto nos damos cuenta de que sus temas siguen siendo los nuestros: la violencia fratricida que aparece en los cuentos de El llano en llamas sigue, desgraciadamente, descomponiendo la vida mexicana. Por otro lado, la figura del cacique Pedro Páramo sigue explicando la figura y la presencia de numerosos presidentes municipales, gobernadores y dirigentes del país; un cuento como "El paso del norte", de mexicanos que son acribillados al tratar de cruzar la frontera con los Estados Unidos, sigue explicando la tensa relación que tenemos con ese país. En Rulfo, entonces, hay un valor testimonial muy grande. Pero eso sí, hay que decirlo, los principales méritos de Rulfo fueron (son) literarios; en lo fundamental fue un gran escritor, un escritor enorme. Pero está también López Velarde.

\section{El poeta Ramón López Velarde...}

Me parece esencial. Es de esos clásicos hacia adentro, es de esos clásicos que no viajan mucho hacia otros países. Murió a los treinta y tres años, era de Zacatecas, nunca conoció el mar, nunca tuvo una casa ni un reloj, murió soltero, les propuso matrimonio a cuatro mujeres, las cuatro estaban enamoradas de él, pero ninguna quiso casarse con él y ellas cuatro murieron también solteras. La sola vida de López Velarde es la vida de un poeta y de eso escribo en mi novela El testigo. Dejó una poesía que retoma ciertos aires del modernismo y los trasciende de un modo popular y conversacional, y se convirtió en el poeta más leído de México. Octavio Paz le dedicó un ensayo luminoso, "El camino de los sentimientos" es el título. No es tan conocido fuera de nuestras fronteras, pero Borges, con esa memoria de elefante que tenía, se aprendió de memoria "La suave patria", un extenso poema de López Velarde.

Vallejo leyó a López Velarde. También al uruguayo Herrera y Reissig. Todos reinterpretaron el legado modernista de una u otra forma.

Es cierto. Pero Vallejo, para nosotros, los mexicanos, es un poeta absolutamente esencial, como lo es la literatura peruana, en especial la poesía. Westphalen, Varela, en fin. De hecho, en una próxima novela, uno de los personajes es una muchacha que es una gran lectora de los poetas peruanos. No voy a decir el título porque, si lo digo, el universo se va a desmoronar, lo siento. 
Tu carrera literaria se ha desarrollado paralelamente a tu carrera como periodista, autor de crónicas y escritor de relatos documentales, de eso que llamamos no ficción. ¿Cómo han convivido esos dos roles en ti? ¿Ha sido una relación armónica?

Por suerte hay un estímulo recíproco entre el periodismo y la literatura, pero, cuidado, que este es un territorio que a veces no está libre de tensiones. Yo me acuerdo mucho de una escena de Conversación en La Catedral, de Vargas Llosa, en la que el protagonista, un joven, entra a trabajar en un periódico, pero quiere ser escritor. De pronto, le ponen una máquina de escribir para que haga periodismo y él siente que le han puesto enfrente un pequeño ataúd. Siente que esa va ser su tumba como escritor, la tumba del condenado a escribir notas policiales o cientos de notas anónimas, muchas de ellas anodinas. En ocasiones el periodismo puede ser, en efecto, la mortaja de un escritor, pero también es un permanente estímulo porque te permite salir de tu mundo, de tu pequeña vanidad de escritor, en la que fabulas sin límite. Ahí llega el periodismo y te obliga a ponerte a prueba con los demás, te hace ver que las razones no las tienes tú, sino los otros. Y como cronista tienes que guardar fidelidad a los otros, ser respetuoso con lo que te dicen, generar un clima de empatía para que logres confianza y te digan realmente lo que piensan. Todo eso pasa por una ética, por un sentido moral que no necesariamente observa el creador de ficciones. No te olvides que se puede ser una pésima persona y un gran artista (risas).

Entrando a otro tema, tú tienes una relación muy estrecha con la literatura alemana, incluso has sido traductor de algunos textos. Pero, además, tuviste una experiencia como diplomático en la antigua República Democrática Alemana. Viviste en Berlín antes de la caída del Muro y después también. ¿Qué recuerdo guardas de esa experiencia tan singular para un latinoamericano?

Durante muchos años el servicio exterior fue una suerte de refugio para los artistas y escritores mexicanos. La política interior mexicana era conservadora, burguesa y por momentos represiva, pero la política exterior era todo lo contrario, muy progresista; baste recordar que apoyó a la República Española y no rompió relaciones con Cuba, se enfrentó en varios foros a Estados Unidos, en fin. Varios escritores, desde Octavio Paz hasta Carlos Fuentes, pasando por Sergio Pitol, Jaime García Terrés y muchos otros, formaron parte del servicio exterior. Cuando Pitol, amigo y maestro, era subdirector de Asuntos Culturales de la Cancillería, me brindó la oportunidad de ir a Berlín, porque yo había sido alumno del colegio alemán y hablaba el idioma, y pensó que esto sería positivo para mí. Llegué a Berlín en 1981. Fíjate, Alonso, que era uno de los momentos más candentes de la Guerra Fría. Fue el tiempo en que en Alemania Occidental se instalaron cohetes de larga distancia que podían llegar sin previo aviso hasta Moscú. Los soviéticos reaccionaron e instalaron cohetes SS20. En esa situación, un conflicto nuclear parecía que podría desencadenarse en cualquier momento; de hecho, hay testimonios 
estrujantes según los cuales eso estuvo a punto de ocurrir. Vivíamos en un clima paranoico, un clima de espionajes y tensiones entre los dos bloques. Hasta yo fui investigado por la Stasi, aunque debo decir que sus reportes eran absolutamente inocuos: la verdad es que mi vida secreta era tan poco apasionante como mi vida pública (risas). Incluso tiempo después de mi salida seguí siendo investigado. Cuando cae el Muro, sorprendentemente, de manera pacífica, se perdió la oportunidad de terminar de una vez y para siempre con los dos bloques y buscar nuevas formas de convivencia. Se optó simplemente por la unificación de las dos Alemanias, algo equivalente a la absorción de una pequeña empresa por otra más grande. Eso provocó la aparición de la idea del fin de la historia de Fukuyama, algo absurdo, porque la historia no tiene fin. Se perdió la oportunidad y caímos en dos extremos, las dictaduras reprobables y el mundo del consumismo. No hubo más.

\section{Igualmente, tienes una experiencia intensa con el periodismo y tu teoría de la crónica como el género "ornitorrinco" es ya célebre.}

A mí me pareció que si la crónica pudiera tener una mascota, el animal que se le ajustaba más era precisamente el ornitorrinco, porque el ornitorrinco parece la suma de muchos animales: es marsupial, tiene pico de pato, tiene aletas, de lejos parece un castor, se dice incluso que el ornitorrinco es un castor diseñado por un comité (risas). Nadie se puso de acuerdo y el ornitorrinco fue construido haciendo una serie de concesiones, y el resultado fue una suerte de Frankenstein. La crónica, del mismo modo, abreva de muchos de ellos, a condición de no ser exclusivamente uno de ellos. La crónica es relato porque nos cuenta una historia, es reportaje porque ese relato está hecho de datos fácticos, es memoria porque muchas veces uno incluye recuerdos personales propios o de otros, es teatro porque puede apelar a diálogos, es ensayo porque más de una vez la crónica planteará argumentaciones. Es una suerte de resumen de distintos géneros, pero tiene una identidad propia; por eso, pensé en ella como el ornitorrinco de la prosa.

\section{Como para no olvidar que América Latina parece la mesa ideal para servir platos híbridos.}

Desde luego que sí, por la cantidad de mezclas culturales que tenemos, especialmente países como Perú y México. Son países con un pasado prehispánico riquísimo, al mismo tiempo una vida colonial (fueron virreinatos los dos) y luego una expansión moderna muy fuerte con contrastes sociales y raciales muy fuertes, con cambios climáticos muy contrastados y con una inmigración fuerte de otros países. Todos esos son rasgos compartidos. Todo esto genera un campo fértil para la crónica y no me equivoco si digo que tanto México como Perú han tenido y tienen excelentes cronistas. 
Actualmente, al menos en América Latina se vive un gran auge de las narrativas documentales, de toda la gama de géneros que constituyen la no ficción. ¿Cómo te explicas esa preeminencia de relatos no solo basados en la realidad, sino dependientes de ella?

Yo creo que el mundo latinoamericano está hecho para la crónica. Tenemos gobernantes pintorescos y muchas veces repudiables, vivimos cotidianamente situaciones de opereta y a la vez enormes sucesos épicos. Yo creo que la mezcla de todo eso se presta muy bien para la escritura de grandes reportajes, ¿no? Por ejemplo, semblanzas de políticos, como ese maravilloso libro de Luis Jochamowitz, Ciudadano Fujimori, un libro ejemplar que retrata a un personaje único, narrado por un cronista que a mi modo de ver es único también. América Latina, como digo, se presta mucho para la crónica, tiene una relación con ella. Ahora lo que ha cambiado mucho es una cultura que nos permite acercarnos de una manera más fluida al género. Así, hoy concebimos que el espacio cultural de la crónica es superior. Cuando García Márquez escribe uno de los grandes momentos de la crónica de nuestro continente, que es Relato de un náufrago, el texto aparece por entregas en el diario El Espectador, por entregas...

\section{Como si fuera un folletín...}

... y sin el nombre de García Márquez. Estamos hablando de 1957. Solo cuando él se convierte en un novelista famoso, se recupera el texto en forma de libro en 1970 y él le cede los derechos de autor al náufrago, como un gesto de empatía, porque además el relato está contado en primera persona, como si hubiera sido contado por el propio náufrago. Bueno, eso explica la valoración cultural que había entonces en relación con la crónica. En su versión original fue un texto que hizo que aumentara la lectoría y las ventas del diario, porque la gente siguió la historia con mucho fervor, con avidez, pero no se consideró que fuera parte de la obra del escritor y eso solo ocurrió a partir de la recuperación del texto.

Aparte de practicar el cuento, la novela, el ensayo y la crónica, tienes también una relación cercana con el teatro. ¿Qué encuentras de fascinante en el teatro?, ¿por qué te interesa el arte dramático?

El teatro tiene algo insustituible y esto lo ha dicho Vargas Llosa: la emoción que produce la palabra en el foro es única y el hecho de que la palabra hablada se convierta en una forma de la acción. En una novela puede haber grandes diálogos y eso contribuye a la conversación, permite que conozcamos a los personajes y todo eso; pero en el teatro decir una cosa que puede ser intrascendente, que sin embargo se carga de pronto de un sentido emocional, define lo que va a pasar. La capacidad que tiene el teatro de darle un presente a la palabra y de convertirla en una acción es algo maravilloso y no me he resistido a este género, que es lo primero que yo escribí, en la adolescencia, imitando 
con un grupo de amigos al gran gurú que teníamos por entonces, que era Alejandro Jodorowsky. Él había militado en el movimiento Pánico, luego se interesó mucho por la era de Acuario...

\section{Fue el creador de la psicomagia...}

Exactamente. Él empezaba a hacer algunos actos teatrales que luego desembocaron en la psicomagia, ¿no? Bueno, él era un gran director de teatro aquí en México, era nuestro gigante. Y lo imitábamos. Hicimos una obra colectiva que se llamaba Crisol. Yo tenía entonces catorce años, participé como actor, como parte de la dramaturgia, pero luego me di cuenta de lo difícil que era hacer teatro porque tienes que conseguir escenografía, actrices...

\section{Toda la producción... es toda una industria...}

Exacto, y hay gente que vende sus coches como parte de los fondos que hay que conseguir para financiar una obra; se trata muchas veces de un martirologio heroico. $Y$ yo, entre que me acobardé y me pareció demasiado difícil entrar en ese mundo, descubrí la ficción como una posibilidad en la que solo se necesitan lápiz y papel para inventar el mundo, y desde entonces me dediqué a escribir cuentos y luego crónicas, pero conservé el amor por el teatro. Produje algunas obras de teatro y mi debut como dramaturgo fue a una edad más bien tardía, de manera que voy a tener una tercera edad dramática (risas).

\section{En relación con tu obra, hay sin duda un éxito inicial marcado por unos libros dirigidos sobre todo a lectores juveniles, pero en el 2004 aparece tu novela El testigo, ganadora del Premio Herralde. ¿Esta novela sería como un parteaguas en tu vida de escritor?}

La vida de un autor está llena de casualidades que le son ajenas y así uno nunca sabe cuándo algo que escribió podrá tener éxito o mayor o menos resonancia. Sin duda, el hecho de que El testigo ganara el Herralde sirvió para darle una presencia fuerte en América Latina porque, desgraciadamente, los latinoamericanos dependemos de la industria editorial española para circular en todos los países. No tenemos editoriales fuertes que circulen fluidamente por toda América Latina. Entonces, cuando un libro obtiene un reconocimiento en España adquiere resonancia, pero yo creo que esto tiene que ver más con cuestiones de la industria editorial y con cuestiones geopolíticas, y no necesariamente con la calidad de los libros. Ya que estábamos hablando de temas peruanos y mexicanos, está el caso de Mario Vargas Llosa, un escritor desconocido, jovencísimo, que escribe una novela espléndida, La ciudad y los perros, muy difícil por su estructura narrativa, que es muy compleja y triunfa en el Premio Biblioteca Breve. Yo me pregunto qué hubiera pasado si esa novela de Vargas Llosa se hubiera publicado en una editorial pequeña de Perú o de México. Probablemente hubiera pasado inadvertida durante un tiempo y quizá 
al paso de los años se haría más conocida y sería el clásico contemporáneo que todos conocemos. En mi caso, al haber obtenido el Herralde, premio de una editorial que tiene más fuerza literaria que económica o comercial -quiero decir que no es una editorial de best sellers, sino de búsquedas y apuestas literarias-, eso provocó que me leyeran un poco más y mi nombre estuviera más presente en Latinoamérica.

¿Cómo son las circunstancias de tu escritura? ¿Estás sujeto a horarios; eres, digamos, un profesional? $¿ 0$ prefieres ciertas atmósferas?

Yo vivo de la literatura y de trabajos paralelos a la literatura. Periodismo, guiones de radio, guiones de cine, traducciones, informes editoriales, etcétera. Todo esto que te acabo de decir se hace en un escritorio, de manera que mi jornada de trabajo, ya que tengo metabolismo diurno, va de las ocho de la mañana hasta, digamos, las dos de la tarde. Ese sería el horario fijo de escritura. Las tardes las reservo generalmente para otras tareas de casa, la familia, leer un poco, hablar por teléfono, en fin.

\section{En La utilidad del deseo hay una frase tuya que dice: "Sería injusto decir que el escritor no disfruta su trabajo, pero sería más injusto decir que lo hace todo el tiempo". ¿Podemos, entonces, ver la escritura como un placer que a veces puede ser incómodo?}

Tienes toda la razón. En ese texto de La utilidad del deseo me refiero a la pasión y a la condena que significa escribir. Uno puede tener un gran entusiasmo por escribir, pero es muy paradójica la relación entre el placer de escribir y la calidad literaria. Muchas veces he escrito con enorme entretenimiento e ilusión textos pésimos. Luego me pregunto cómo pude estar tan contento escribiendo algo de mala calidad, como un sonámbulo engañado en otra realidad. Otras veces uno se esfuerza mucho, sufre y se siente insatisfecho, y a la postre eso resulta mejor. Lo que quiero decir es que no hay relación entre una cosa y la otra. Es cierto que uno disfruta escribiendo, pero a veces uno se equivoca al escribir disfrutando, así como es cierto que uno sufre muchas veces y en ocasiones hay un buen resultado. Como todo en la vida hay momentos de quiebre también. A mí me parece sumamente complicado aceptar un anticipo por una obra que no he escrito...

\section{A lo Balzac...}

Exactamente, lo que pasa es que Balzac tenía una capacidad prolífica que obviamente yo no tengo. Balzac sabía perfectamente cómo iba a terminar un libro que había concebido apenas algunas semanas antes. A mí me ocurre que puedo escribir con enorme fluidez durante un tiempo y luego me atoro en un detalle que puede parecer o ser menor, que no define una trama y que, sin embargo, puede ser insalvable durante meses. Entonces tú ya tienes el compromiso de entregar el texto y hay una pequeña tontería que no te deja avanzar y de verdad que es algo muy extraño, porque no se entiende cómo se puede 
pasar de escribir a gran velocidad a ser el más lento de los autores. Todos estos placeres y frustraciones, estos gustos y disgustos, son los que conforman el oficio de escribir, un oficio emparentado con cualquier otro que dependa tanto de la pasión.

\section{¿Cuál sería para ti el lugar social de la literatura?}

Me parece que la literatura ya no tiene el lugar social que tuvo, por ejemplo, en el siglo XIX, cuando la novela era el príncipe de los géneros o cuando todo el mundo iba al teatro para enterarse de cuáles eran las discusiones sociales importantes. Todavía en la primera mitad del siglo xx, y quizá hasta los años sesenta, la cultura en general y la cultura en particular tuvieron un peso fuerte, como lo demostró la generación del boom, que además tuvo orientación política, cambiante, es verdad, dependiendo de cada uno de sus miembros. Yo diría que esta generación fue la última en tener una influencia social tan grande y relevante, al grado de que Mario Vargas Llosa terminó siendo candidato a la presidencia del Perú; eso es algo difícil de ver en los escritores de hoy.

\section{Y es algo que recuerda a esos escritores patricios del XIX, precisamente.}

Exacto. Y eso tenía que ver con figuras como Octavio Paz, que era una persona que uno leía para ver cuál era la orientación, el rumbo del país. Paz dictaba un poco la manera de interpretar la realidad, era un caudillo cultural.

\section{Un intelectual público.}

Exactamente eso. Esa figura del intelectual público ha sido muy importante en América Latina y especialmente en países como México y Perú. Yo creo que, actualmente, por fortuna, el escritor está relegado a un plano menos protagónico en lo social, y digo "por fortuna", porque creo que se comete un error al pensar que una persona que domina una forma de la dificultad que es la escritura, en países que tienen mucho analfabetismo o analfabetismo funcional o bajos niveles de cultura, pensar - digo- que esa persona tiene una especie de bola de cristal con la cual puede adivinar el futuro, y fácilmente se convierte en un profeta y puede caer en la tentación de hablar de algunas cosas de las que no sabe nada. He escuchado a muchos intelectuales latinoamericanos hablar de los problemas más diversos sin saber nada de ellos y yo mismo, algunas veces, he incurrido en esa irresponsabilidad de hacer eco de opiniones de las que no estoy totalmente convencido o seguro. Todos somos proclives a hablar más de la cuenta. Una sociedad, en la medida en que se va haciendo más culta, entenderá mejor al escritor como un productor de literatura y no como una figura pública privilegiada. Me parece bien que el escritor ya no sea esa especie de mesías, aunque sí creo en el papel de la intervención pública. 
Has mencionado a una figura crucial, que es Octavio Paz. Pensaba, antes de tener esta conversación contigo, en preguntarte por la identidad mexicana y si El laberinto de la soledad te sigue pareciendo un libro vigente.

En México costó mucho trabajo pensar o razonar que teníamos una identidad propia. En 1915, Martín Luis Guzmán escribe un libro precursor, titulado La querella de México, donde se preguntaba cuál era el papel del criollo, cuál era el papel del indio, por qué teníamos tantos complejos unos respecto a otros y hablaba de estas debilidades que impedían que tuviéramos un proyecto de nación unitario. Desde 1915 hasta 1950, que es cuando Paz publica El laberinto de la soledad, hay muchos ensayistas que se dedican a la filosofía y la psicología del mexicano y, de alguna manera, Octavio Paz con una prosa magnífica remata con broche de oro esta tradición. Pero el propio Paz advierte que el mexicano no es siempre de la misma manera; el mexicano no puede ser como el maíz mejorado, en el que todos los granos son idénticos, hay muchos modos de lo mexicano. Para corregir la posible distorsión de sus ideas, escribió luego otro libro titulado Posdata, donde advierte que el mexicano no es una esencia, sino una historia; es decir, el mexicano tiene ciertas características, pero va cambiando con el tiempo. Y creo que el objetivo de El laberinto de la soledad no era decir que el mexicano era único o diferente y que debemos reconocernos casi como extraterrestres, sino que en la medida en que aceptemos nuestras diferencias podremos participar de manera más fluida y rica en el concierto de las naciones y en la discusión con las demás personas. Es una invitación para asumir la diferencia y participar con ella en la colectividad de la cultura. Claro que la sociedad mexicana ha cambiado, se ha hecho más compleja e híbrida, pero no ha dejado de haber reflexión sobre la identidad, que es un deporte nacional. En 1987, Roger Bartra publica La jaula de la melancolía, que es una crítica justamente a la sobredosis de mexicanidad. El debate no se ha cerrado y se abre a nuevas variantes que me parecen interesantes. Por ejemplo: los intelectuales indígenas. Durante mucho tiempo estos discursos fueron hechos por hombres blancos; ahora hay mujeres indígenas reflexionando sobre estos temas. De hecho, la intelectual más novedosa que tenemos en México es de la comunidad mixe, ella es Yásnaya Aguilar Gil, una espléndida ensayista y lingüista. Así como ella hay otros intelectuales indígenas que están pensando y planteando otros proyectos de nación, como el propio proyecto zapatista, que habla de un proyecto integrador, de un mundo en el que quepan muchos mundos, un México incluyente; ellos han dicho: "Nunca más un México sin nosotros". Ellos buscan esa unidad respetando las autonomías indígenas; es como entender El laberinto de la soledad a nivel intrahistórico, no como México hacia las demás naciones, sino respetando la diferencia de cada comunidad indígena (hay más de sesenta en México) dándoles autonomía y con esos elementos construir un mosaico multicultural. Es un proyecto sumamente interesante. En Oaxaca las comunidades mixe proponen otra cosa; ellos proponen un pueblo sin México, no desean estar unidos al membrete de "México criollo"; lo que se busca es una unión de pueblos libres, 
es algo que va más allá de lo pensado por los zapatistas. Entonces, esta discusión está viva y se va a discutir mucho cuando se cumplan 500 años de la caída de Tenochtitlán. Lo interesante es que ya no se habla de los indígenas como de grupos que nos dejaron algo en el pasado, sino que se trata de un componente contemporáneo de nuestro país. Hay mucho por escribirse sobre esto.

\section{Tú conociste a Roberto Bolaño y tuviste amistad con él. ¿Qué es lo primero que recuerdas de él?}

Lo primero que recuerdo es su gran sentido del humor, su capacidad para hacer bromas y travesuras, el gusto por hacerlas. Siempre he pensado que el sentido del humor es atributo de la inteligencia y Roberto era malévolo, sarcástico, divertido, eso lo caracterizaba. Desde el primer momento que lo conocí fue así. Yo tenía dieciséis años, él tendría dieciocho. Concursamos en una revista para jóvenes que publica la universidad hasta ahora, la revista se llama Punto de Partida. Roberto obtuvo el tercer lugar en poesía y yo el segundo en cuento. El día de la premiación yo estaba conversando con uno de los jurados, el escritor chileno Poli Délano, que vivió exiliado en México varios años. Fue entonces cuando Roberto se acercó a saludar a Délano y trabamos amistad. Él recuerda esto en su libro Entre paréntesis. Fuimos muy cercanos, aunque el contacto se fue espaciando porque él se fue a España. Lo vi más cuando comencé a frecuentar más Barcelona. De hecho, cuando muere en el año 2003, yo estaba viviendo en Barcelona. Una pérdida para todos nosotros, un amigo extraordinario. Sueño con él. Aparece en mis sueños y me dice cosas, se burla de mí, lo hace con palabras que solo podría usar él.

\section{¿Qué autores y autoras latinoamericanas de hoy te parecen más interesantes?}

Muchos. Hay un novelista mexicano, Jorge Comensal, autor de una novela Las mutaciones. Las escritoras me interesan mucho. Aquí en México, Guadalupe Nettel, Valeria Luiselli, Cristina Rivera Garza; en Argentina, Mariana Enríquez y Samanta Schweblin; en Chile, Lina Meruane. Me gustan mucho Sara Mesa, de España, y Gabriela Wiener, de Perú. Es un magnífico momento para las escritoras latinoamericanas.

\section{Finalmente, ¿por qué o para qué escribe Juan Villoro?}

Yo escribo por necesidad, no tolero el mundo sin estarlo escribiendo. El mundo me parece imperfecto, me parece que está mal hecho y para compensar sus carencias y lacras trato de agregarle algo diferente, que muchas veces es doloroso o que puede producir una satisfacción para mí en el momento de escribir, y espero que también para alguien en el momento de leer. 